\title{
Improving international student transition to professional employment
}

\section{Dorothy Wardale}

Faculty of Business and Law, Curtin University, Western, Australia.

\begin{abstract}
This paper draws its data from two sources: a literature review of the enablers and barriers to a successful transition by migrants and international students to a professional career; and a case study of 14 post-graduate students in an Australian public university. The case study includes interviews with two students of their perception of the transition to employment. The paper identifies ten considerations for universities and students seeking to maximise success, and to minimise the time taken, to transition to a career in the Australian workforce.
\end{abstract}

Keywords: career transition, graduates, international students. 


\section{Introduction}

Australia is increasingly reliant on international education as a revenue stream (Blackmore et al., 2014), making up 1 in 5 students in Australian universities (Norton and Cherastidthan, 2018). Fees from international students in Australian universities are the single biggest source of university revenue (Norton and Cherastidthan, 2018); and international students injected A \$32 billion into the Australian economy in 2018 (Australia Universities, 2018).

Australia's appeal to many international students includes accreditation and rankings along with the ability to apply for a post-study work visa for between two and four years for themselves and immediate family members. Some use this time to apply for Permanent Residency (PR) and subsequently citizenship. Some graduates see time in Australia as a 'temporary stop' (Aten et al, 2016) taking low-skilled work, however, others want to use their degrees to transition to professional work in Australia. In Australia, most immigration is employment-based (Chand and Tung, 2019). Therefore, for those wanting to remain in Australia, there is a strong desire to win professional work.

Against this backdrop, international students under-perform their domestic counterparts in the transition to work (Gribble et al., 2016). A 2015 study identified that $40 \%$ of internship providers (potential employers) were unhappy with the 'work readiness' of international student placements with respect to business acculturation, ability to handle unfamiliar problems and communication skills (Jacking and Natoli, 2015).

The aim of this research is to explore what universities may do to help improve international students' transition to professional employment. The paper describes some of the barriers and enablers facing international students seeking a transition to employment in Australia. A case study is provided, including interviews with two Indian alumni who have self-identified career success. The themes of their perceived success is compared to the literature and eight suggestions are offered for universities.

\section{Literature Review}

Career success may be defined as a perception of accomplishment and performance (Turchick et al., 2010). This can be viewed objectively, where a career shows tangible progression through roles and positions; or subjectively, where a career reflects the individual's sense of their optimal career path (Connell et al., 2009). Thus career success is largely self-assessed without clear a definition of what constitutes a right or wrong path. However, we know that migrants experience barriers to starting, or re-establishing, their professional careers in a host country (Connell et al, 2009). The following sections outline some of the barriers and enablers to career success. 


\subsection{Barriers}

This section outlines four key barriers, identified in the literature, facing international students and migrants attempting to transition to their new country's workplace. The literature chosen is largely drawn from Australia and Canada. First, some students have an expectation that a higher education degree will automatically lead to professional employment (Chen, 2014). They rely on improving their human capital without a commensurate improvement in their social and/or cultural capital (Blackmore et al. 2015). Blackmore et al. (2015) suggest that employers expect good qualifications along with other employability skills such as communication, teamwork and problem solving; and community experience and travel are also valued for higher status roles.

Second, a lack of network connectivity is a barrier. An international student seeking to transition to work in a host country may lack access to a network of associates from school, work, family, or their own social relationships. Ibarra (1993) discussed the difficulty of students building homophilious networks among their peer group because of the relative lack of cultural diversity in organisations, whether universities or employers. Yet we know that jobs are more likely offered to 'people like me' or to those with whom employers can identify (e.g. Minefee et al., 2018). A small or limited network contributes to a lack of access to highstatus individuals who may be able offer work directly or through an acquaintance (Turchick et al, 2010).

Difference is third issue, and refers to the different language and cultural norms, and to the discrimination that may occur as a result of a difference, or the perceived difference. Turchick et al. (2010) discuss employers believing a local accent to be advantageous and that some employers being uncomfortable with ethnic minorities, especially those from non-European backgrounds. Blackmore et al. (2015) suggest that, 'International students are excluded from the employment due to their perceived cultural dispositions, lack of experience in the field, inability to acquire or act in particular forms of strategic knowledge or rules of the game' (pp 73).

Finally, the concept of 'Transition Penalty', or the period of adjustment required for a migrant to establish himself or herself in a new country (Connell et al, $2009 \mathrm{pp} 473$ ). This can be seen as wasted talent (Aten et al, 2016), or underemployment (Turchick et al, 2020; Connell et al, 2009) where a skilled migrant may experience a lack of recognition of existing qualifications and experience and be employed in low-skilled roles with limited work experience and mobility, leading to underemployment and less working hours than desired (Chand and Tung, 2019). 


\subsection{Enablers}

On a positive note, three key enablers of transition are noted from the literature; their order below does not reflect importance. First, the personal qualities of individuals seeking work in a new country. These include being able to establish and maintain career motivation, resilience and positive self-identity (Turchick et al, 2019, Zikic et al., 2010). Several authors discuss the importance of career self-management (e.g. Jackson \& Wilton, 2017) and the need for students to be proactive in finding the right job. Both Turchick et al, (2010 and Hawthorne, (2006) amongst others, discuss 'blindness to racism' as an enabler. This occurs when a migrant uses cognitive buffers to manage and minimise negative effects of discrimination. In Australia and Canada, a clear enabling skill is to acquire English language competence and cultural capital. This is likely to happen when individuals mix with others from a variety of cultures, but especially the host country (Blackmore et al. 2015). Students with the discipline to navigate this process for attaining a visa shortly after graduation are able to transition quicker than those who do not.

Second, personal networks are vital for a transition to work. Just as a lack of networks and extended social capital may be a barrier, their presence is seen as an enabler (Blackmore et al., 2015, Zikic et al., 2010). Aten et al. (2016) also point out that these networks may extend from people in their home countries that have connections or influence in the new country.

Finally, participating in development opportunities in a new country assists the transition to work. These include enrolling in local training, and education to acquire local credentials and develop a network (Aten et al., 2016; Zikic et al., 2010). These might include mentoring from local residents where cultural awareness, and an introduction to a network had greater significance than skill development. Likewise, gaining meaningful work experience in the host country increases the migrant's ability to apply for higher-level roles (Connell et al. (2009).

Al Ariss (2010) outline four modes of engagement that migrant professionals may use for managing the contextual barriers of winning work: Maintenance, refers to migrants who recognise the barriers to success and work within them to reach their desired role; Transformation refers to those migrants who see the barriers and seek to alter them; Entrepreneurship refers to those migrants who start up their own businesses to avoid the barriers; and Opting-out refers to those migrants who return home or work purely for income but not in their target career. Against this backdrop, we introduce and compare our case study participants. 


\section{Participants}

The case study was of 14 postgraduate alumni from a public sector Australian university. They came from Finland, the USA, Vietnam, Iran, and Hong Kong with most from India. Different alumni had different reasons for studying in Australia, varied Australian career aspirations and varied plans to remain in Australia. All participants engaged in a three-month university-coordinated internship. Five of the 14 participants won professional roles within 3 months of graduating. Two of this group participated in semi-structured interviews of around one hour each. They were both Indian and selected both as self-identified career successes; and because Indian students were in the majority for the case study group. Indians were also the second largest proportion of onshore international students in Australia in 2016 (15\%) following China (Dept. of Education, 2017; ABS, 2017). The two graduates were both engineers, approximately 30 years of age with significant Indian work experience and they wished to become consultants. Both were offered contract work with their internship employer. They have continued to work with this employer, amongst others, on a contract basis as consultants. To date, their clients have been drawn from their networks, and their goal is to continue as private consultants until they have an opportunity to join a large consultancy firm.

\section{Findings}

Anecdotal feedback from the broader case study group and the two in-depth interviews revealed perceptions of the biggest obstacle to gaining employment in Western Australia (WA) was their visa status and immigration position. Their experiences suggested that most organisations required clear proof of a right to work in Australia. They noted that jobs on the LinkedIn platform, even with no applicants, had the same requirement.

A second barrier they identified was time devoted to building networks and understanding local norms. Grad 1 suggested that 'The amount of time spent by an international student in WA is directly proportional to the employment opportunities created for oneself.' The two interviewees perceived that that the more time international students and graduates devoted to attending network events and gaining social skills, the easier the transition to work. For example, Grad 2 suggested,

'The wider the culture differential between the international student and the WA way of life, the longer the adaptability to social cues and the work culture of the organisations. International students who are more open to change, and embrace it to socialise easily, are accepted into the workforce faster. For some internationals, it takes a lot of time to pick the necessary social skills.' 
Of the 14 students in this case study, those who invested time in developing local networks were more successful in winning professional work and at a faster rate than those who did not. One of those interviewed suggested that time barriers limited the development of valuable network connections. Grad 1 reported, 'WA (Western Australia) is a close-knit work community. ... establishing a valued network of individuals who can help you transition into employment is a huge and time-taking task which international students are short on while studying.'

Having a plan to transition into the workforce was seen as an enabler. Many international students had a linear approach to winning work that was sub-optimal in that they waited until recuperating from completing their degree before starting the visa application process. Whereas, those students who developed a plan to counteract the visa issue and other barriers to work, not only built self-confidence but also saved time. All five of the graduates who were successful in winning professional work had started their visa application process prior to graduating. Grad 1 cited one international student who did not plan his work visa application process post degree: 'The organisation which offered him a position contingent on a visa, rescinded the offer after waiting for several weeks.'

Personal characteristics of pro-activeness and perseverance were cited as reasons for success. Grad 1 suggested that, "As an introvert, I had to make a conscious effort to become an extrovert in social events. This was done to be able to sustain networks established in the class and to expand the number of valuable external network connections'. Perseverance was another personal characteristic identified. Graduates discussed that applying for jobs can be demoralising generally, so for the international graduate who needs a high return on their investment it can seem even more daunting. Several graduates spoke with the researcher sharing their frustration and the effort required. Grad 2 suggested that, 'We have persevered through difficult projects, at lower pay to prove our worth and make our work speak louder than our race, ethnicity and English-speaking abilities. One international student ... struggled for months, every day after graduation, but landed a job five months after graduation. ... the ideal position can take months ...'.

Finally, good performance was also considered an enabler. Across the 14 students, there seemed to be a positive correlation between students with good grades and those who successfully transitioned to work. Grad 2 suggested 'Performing well in individual areas of interest not only increased subject expertise but also built up our confidence to perform better for interviews and formal interactions'. 


\section{Discussion and Recommendations}

Many universities have active Work Integrated Learning (WIL) programs, and the literature and findings from this research indicates many of the issues of transition are known. Yet, international students continue to underperform against their domestic counterparts when transitioning to professional employment. The following discussion outlines eight insights into what universities can do to improve career success for willing students, whilst also acknowledging that students need to participate in their own career self-management.

First, acknowledge that students have varied reasons for studying in a foreign country and not all will want to transition to professional work after graduation, therefore, there is value in identifying students who plan to apply for a visa and a professional career and to invest extra effort with this group.

Second, it is important that students are encouraged to multi-task in transitioning to professional work. Explain that the transition to work is not a linear process and that they need to build their networks at least 18 months out, and start the visa application process in their final semester.

Third, assist students with a strategic career planning, including networking. Such plans should aim to engage with people outside the student's cultural group, especially were local language is spoken; and with industry and recruitment companies. This can be achieved through recruitment events, career fairs, industry guest speakers and industry forums.

Fourth, provide wrap-around workshops and activities on strategies for winning work. These might include workshops or online resources for building capability with LinkedIn, CV writing, interview skills, networking with industry and communication with non-peers.

Fifth, invite immigration authorities to speak on the process for post-study work visa applications. The focus of these presentations needs to be on content and clarity around timelines.

Sixth, highlight that good grades alone will not guarantee a job. Employers are looking for quality and breadth in their talent search, which includes at least communication skills, teamwork, and problem solving skills; and may also include signs of commitment to their new community through evidence of volunteering and other community involvement.

Seventh, employers are looking for students with meaningful project-based work experience not tick-the-box internships where the work may be menial. A university that offers opportunities for significant work experience to final year students will have a marketing edge. 
Finally, council students to consider various modes of engagement with work open to them. Some students may be unrealistic about their options, while others are prepared and plan to work their way to their preferred role, or to start their own business.

\section{Conclusion and future research}

A literature review of largely Australian- and Canadian-centric research has been contrasted with a small case study from one Australian university. The outcome is eight considerations for universities seeking to improve student success in a transition to professional employment. There is scope to enlarge the case study, complete more interviews and work with international colleagues interested in this area to expand the field of participants and the international focus of the work.

\section{References}

Aten, K., Nardon, L., \& Isabelle, D. (2016). Making sense of foreign context: Skilled migrant's perceptions of contextual barriers and career options. International Journal of Cross Cultural Management, 16(2), 191-214.

Al Ariss, A. (2010). Modes of engagement: migration, self-initiated expatriation, and career development. Career Development International, 15(4), 338-358.

Australia Universities (2018) https://www.universitiesaustralia.edu.au/mediaitem/international-students-inject-32-billion-a-year-into-australias-economy-boostingaussie-jobs-and-wages/

Blackmore, J., Gribble, C., \& Rahimi, M. (2017). International education, the formation of capital and graduate employment: Chinese accounting graduates' experiences of the Australian labour market. Critical Studies in Education, 58(1), 69-88.

Chand, M., \& Tung, R. L. (2019). Skilled immigration to fill talent gaps: A comparison of the immigration policies of the United States, Canada, and Australia. Journal of International Business Policy, 2(4), 333-355.

Chen, M. (2014). Informal employment and development: Patterns of inclusion and exclusion. The European Journal of Development Research, 26(4), 397-418.

Connell, J., Burgess, J., Fang, T., Zikic, J., \& Novicevic, M. M. (2009). Career success of immigrant professionals: Stock and flow of their career capital. International journal of Manpower.

Gribble, C., Rahimi, M., \& Blackmore, J. (2017). International students and post-study employment: the impact of university and host community engagement on the employment outcomes of international students in Australia. In International Student Connectedness and Identity (pp. 15-39). Springer, Singapore.

Hawthorne, L. (2016). Labour market outcomes for migrant professionals: Canada and Australia compared. Available at SSRN 2808943.

Ibarra, H. (1993). Personal networks of women and minorities in management: A conceptual framework. Academy of management Review, 18(1), 56-87. 
Jacking, B., \& Natoli, R. (2015). Employability skills of international accounting graduates: Internship providers' perspectives. Education+ Training, 57(7), 757-773.

Jackson, D., \& Wilton, N. (2017). Perceived employability among undergraduates and the importance of career self-management, work experience and individual characteristics. Higher Education Research \& Development, 36(4), 747-762.

Minefee, I., Rabelo, V. C., Stewart IV, O. J. C., \& Young, N. C. J. (2018). Repairing leaks in the pipeline: A social closure perspective on underrepresented racial/ethnic minority recruitment and retention in business schools. Academy of Management Learning \& Education, 17(1), 79-95.

Norton, A., \& Cherastidtham, I. (2018). Mapping Australian Higher Education. Gratton Institute.Australia.

Turchick Hakak, L., Holzinger, I., \& Zikic, J. (2010). Barriers and paths to success: Latin American MBAs' views of employment in Canada. Journal of Managerial Psychology, 25(2), 159-176. 